\title{
Ránula Sublingual - Un Caso Clínico
}

Fecha de Recepción

02 de mayo de 2012

\section{Aceptado para su publicación}

08 de agosto de 2012

\section{Viviana Karaben}

Auxiliar Docente Farmacología.

Jorge Gabriel Becchio

Auxiliar Docente Cátedra Cirugía III Buco Máxilo Facial

María Silvia Almirón JTP. Anatomía Patológica

\section{Sebastián Solé Desimoni}

Auxiliar Docente

Cátedra Físico Química Biológica

Prof. Roque O. Rosende

Prof. Titular Catedra Cirugia I Tecnicas Quirurgicas y Anestesicas.

\section{Resumen}

La ránula del suelo de boca es una entidad de poca frecuencia y de etiología controvertida. Se observa a distintas edades pero es más frecuente en niños, adolescentes y adultos jóvenes con características clínicas propias que la diferencian de otras entidades de la boca. Se presenta el caso clínico de una niña de II años de edad al que se le realizó como tratamiento el método de marsupialización.

Se realizan comentarios acerca de la frecuencia de aparición de esta lesión, sus características clínicas, su diagnóstico y el tratamiento quirúrgico realizado.

\section{Palabras Claves}

Ránula sublingual, Seudoquiste, Glándulas salivales.

\section{Summary}

The ranula of the soil of the mouth is an entity infrequently and controversial etiology is observed at different ages but is most common in children, adolescents and young adults with clinical features of their own, which distinguish it from other entities in the mouth. A case of an II year old girl who was made a treatment called method of marsupialization. Comments are made about the frequency of appearance of this lesion, clinical features, diagnosis and surgical treatment. 
Key words

Sublingual Ránula, Seudoquiste, Salivary Glands.

\section{Resumo}

A rânula do solo da boca é uma entidade de pouca frequência e etiologia controversa, é observada em diferentes idades, é mais comum em crianças, adolescentes e adultos jovens com características clínicas próprias que o distinguem de outras entidades na boca. Apresenta-se o caso de uma menina de II anos de idade ao que se the realizou como tratamento o método de marsupializació.

São feitos comentários sobre a freqüência de aparecimento da lesão, características clínicas, diagnóstico e tratamento cirúrgico.

\section{Palavras chaves}

Rânula sublingual, pseudocisto, glândulas salivares.

\section{Introducción}

La ránula es una formación quística de transparencia azulada de contenido mucoide semejante a la clara de huevo, que se desarrollan a nivel de las áreas salivales de las glándulas sublinguales y submaxilares en piso de boca'.

Aparecen como pseudoquistes y se producen por la acumulación de saliva en el tejido conjuntivo, a causa de la degeneración del tejido salival. Se observa a diferentes edades en un rango entre los 3 y 62 años $^{2}$. Su frecuencia es mayor en niños $y$ con un predominio en el sexo femenino y en personas profesionales del canto y charlistas, así como también se ha observado en algunos pacientes con antecedentes de irritaciones, traumas y estomatitis'.

Los traumatismos y la obstrucción de cualquiera de los 20 conductos de la glándula sublingual o el conducto de Wharton de la glándula submandibular provocan esta alteración. La obstrucción puede suceder debido a un sialolito, que está formado por precipitación de sales de calcio de la saliva alrededor de la mucina que se acumula en cualquier punto del conducto salival. El traumatismo puede producirse de manera accidental o por un acto quirúrgico, el cual secciona el conducto salival y extravasa el contenido hacia los tejidos circundantes, provocando una reacción inflamatoria ${ }^{3}$.
Los ductos acinares de las glándulas sublinguales se llaman ductos de Bartolini, y la mayoría de las veces se unen para formar de $\mathbf{8}$ a 20 ductos de Rivinus; estos ductos son cortos y de pequeño diámetro y se pueden abrir directamente en el piso anterior de la boca en una cresta de mucosa conocida como la plica sublingualis, 0 abrir indirectamente por medio de conexión de conducto submandibular y después de la cavidad bucal por medio del conducto de Wharton 4 .

Desde el punto de vista clínico puede presentarse en forma unilateral aunque a veces traspasa la línea media ocupando parte del lado opuesto transformándose en bilateral de forma, ovoide, generalmente situada entre la lengua y el maxilar inferior, por lo general en uno de los lados del frenillo; puede alcanzar de 2 a $5 \mathrm{~cm}$ de diámetro, es transparente y violácea, de consistencia blanda a la palpación muestra su contenido líquido sin gran presión, es asintomática, pero cuando alcanza un tamaño considerable puede interferir en el habla y la alimentación ${ }^{5}$. La pared de la ránula es muy delgada fácilmente lacerable de superficie lisa y brillante, al romperse, deja de escapar un líquido seromucoso, incoloro, viscoso como clara de huevo, raramente sanguinolento, en su composición se encuentra mucina y albúmina .Su evolución es lenta y siempre benigna. EI diagnóstico clínico resulta siempre evidente y no es necesario realizar técnicas de imágenes ${ }^{2,1}$.

La ránula sublingual superficial o por retención está situada por encima el músculo milohioideo $y$ se traduce por edema intrabucal. Cuando la ránula es profunda, el edema se extiende a través del milohiodeo y se exterioriza por edema de la región suprahiodea lateral o submaxilar, esta es una variante poco común llamada ránula plunging o ránula cervical, la cual surge cuando la mucina diseca el músculo milohioideo y produce un crecimiento hacia abajo a la zona del cuello.

Esta entidad constituye un tipo quístico raro, por lo general congénito, que se encuentra tapizado por un epitelio cúbico o cilíndrico que parece tener su origen en restos embrionarios o en la parte más profunda de la glándula sublingual, por lo que el diagnóstico es muy dificil ${ }^{6,3}$.

Al realizar el examen histopatológico, impresionan sus paredes por su delicada consistencia; en la superficie están unidas a la mucosa del suelo de la boca, de la cual es muy dificil separar. El exa- 
men microscópico demuestra que está formada por una fina pared de tejido conjuntivo fibroso comprimido con algunos elementos de tejido de granulación. Cuando se forma a expensas de un conducto dilatado, pueden observarse restos de este en un tapizado epitelial. Se diferencia del angioma por ser más firme; de los quistes dermoides porque estos presentan una consistencia pastosa y son más frecuentes en la línea media; los lipomas son más firmes; y los quistes del conducto submaxilar, generalmente provocan tumefacción de la glándula, se desarrollan más rápidamente que la ránula y provocan dolor y tumefacción.

Para establecer el diagnóstico se realiza radiografía oclusal, para descartar la presencia de sialolito, y un ultrasonido para demostrar la presencia de una cavidad y sus límites anatómicos. El manejo paliativo consiste en masajes y sialagogos (estimuladores de la salivación), con el fin de que se desaloje el tapón que está obstruyendo el conducto afectado ${ }^{3}$.

La escisión quirúrgica es el tratamiento usado más frecuentemente, pero tiende a recurrir con facilidad si la extirpación quirúrgica no es completa, de allí que se hace necesario la total remoción de la lesión 7 . La marsupialización es usada en las ránulas y consiste en la eliminación de la porción superficial de la lesión y de la mucosa circundante, luego de hacer varias incisiones superficiales con cortes circulares en todo su espesor. En los casos de ránulas émbolos la mayoría de los autores recomiendan la remoción quirúrgica de la glándula sublingual, también se ha utilizado con bastante éxito la criocirugía con nitrógeno líquido la cual reduce el riesgo de infección en el período postoperatorio, además de disminuir el dolor de la herida ${ }^{8}$.

Es importante el interrogatorio del paciente para la realización del diagnóstico ya que la existencia de traumas previos, unido a una clínica de aparición súbita, aumento y reducción del tamaño de la lesión, de color azulado o amarillento y de consistencia blanda o renitente nos orientan en el diagnóstico clínico, el cual debe ser confirmado por la toma de la biopsia y debe hacerse la remoción total de la lesión con el fin de evitar las recidivas?

\section{Presentación del Caso}

Se trata de una niña de II años de edad que concurre a la consulta acompañada de sus padres por presentar en el lado derecho de piso de boca un aumento de volumen de más de $4 \mathrm{~cm}$ de diámetro de color azul-violáceo, indoloro de consistencia blanda a la palpación que nos orientaba clínicamente a un diagnóstico de ránula sublingual. La lesión presentaba un comportamiento cíclico, con fases de desaparición y exacerbación.

Se realizaron análisis complementarios de hematología con valores normales y se decidió la intervención quirúrgica previa medicación antibiótica. Luego de la antisepsia extraoral e intraoral, se aisló el campo operatorio y se realizó anestesia de la zona mediante el bloqueo bilateral del nervio lingual.

La técnica quirúrgica de elección fue la de marsupialización de Partsch o técnica de marsupialización, que consiste en la extirpación de la pared superior de la ránula, luego de hacer varias incisiones superficiales con cortes circulares en todo su espesor y posterior sutura de la membrana quística a la mucosa del piso de la boca para hacer que continúe con la cavidad bucal.

Se envió la muestra obtenida al Servicio de Anatomía Patológica de la FOUNNE en un frasco con formol al 10\%: rotulado con el protocolo de biopsia correspondiente.

El estudio de la macroscopía describe la recepción de una losange de I,5 por 0,6 y otro fragmento nodular de $0,5 \mathrm{~cm}$ de diámetro.

Microscópicamente las secciones muestran fragmentos de mucosa con solución de continuidad del epitelio que corresponde, en profundidad a pseudocavidad quística tapizada por tejido de granulación y luz de contenido mucoso. Adyacente al mismo se reconocen numerosos lobulillos glandulares mucosos con dilatación de conductos excretores.

El examen histopatológico confirmó el diagnóstico presuntivo de ránula (mucocele por extravasación).

\section{Discusión}

Para la realización de la técnica quirúrgica, Kruger $^{10}$ realiza la sutura del suelo de la boca al epitelio quístico antes de la escisión del techo de la ránula, y enuncia que es posible remover una 


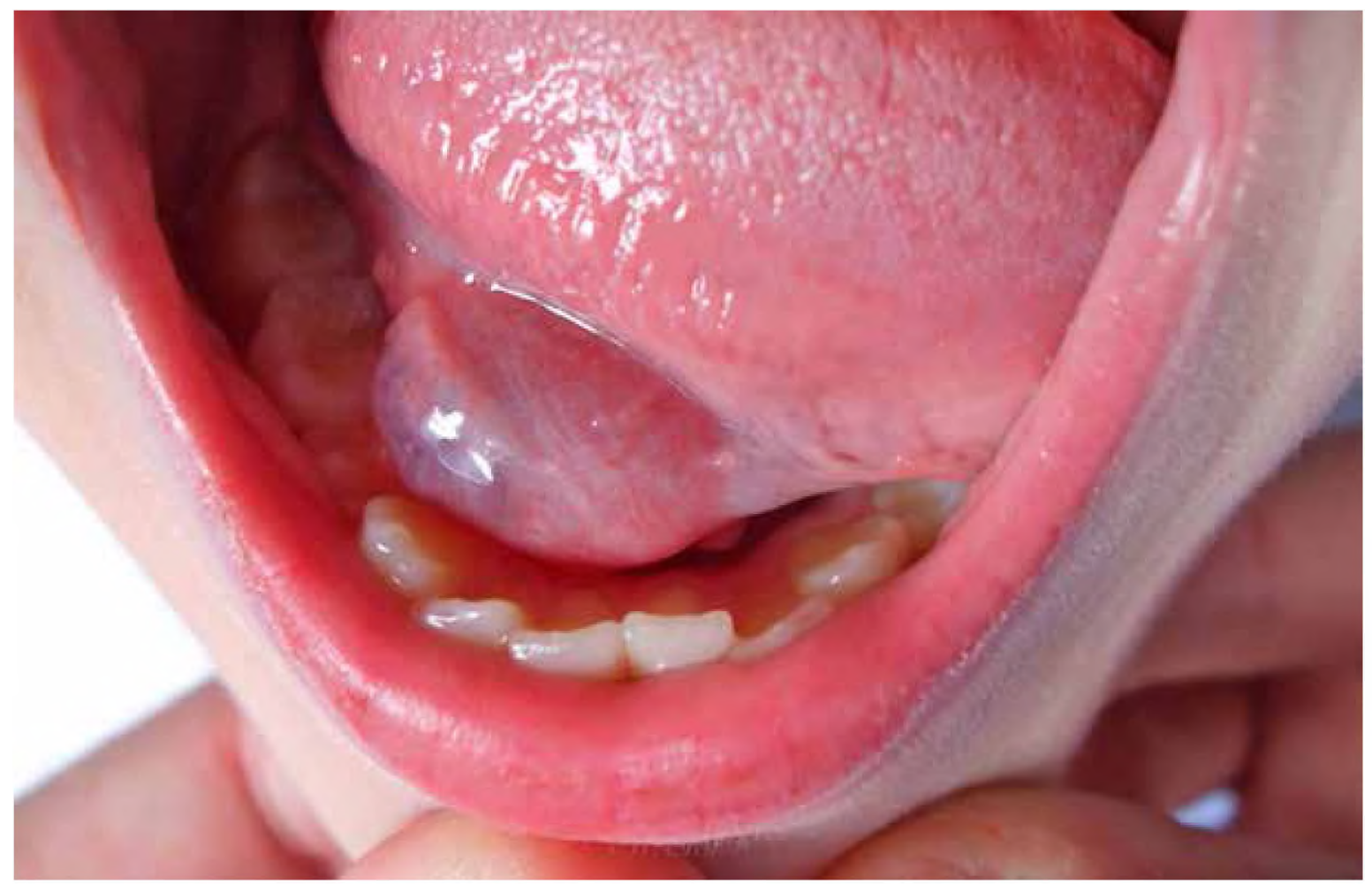

Aspecto clínico de la Ránula

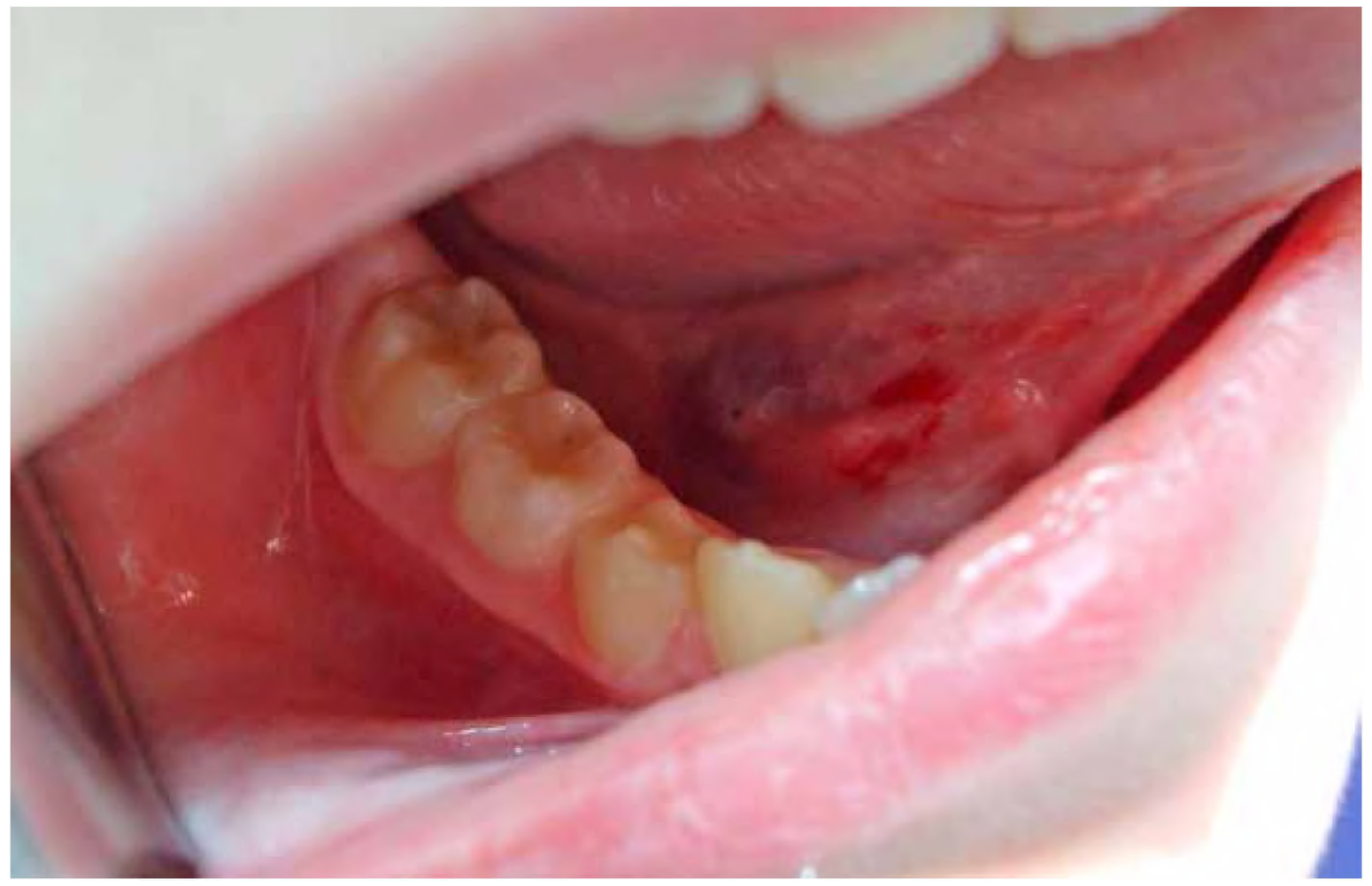

Orificio de drenaje del contenido seromucoso. 


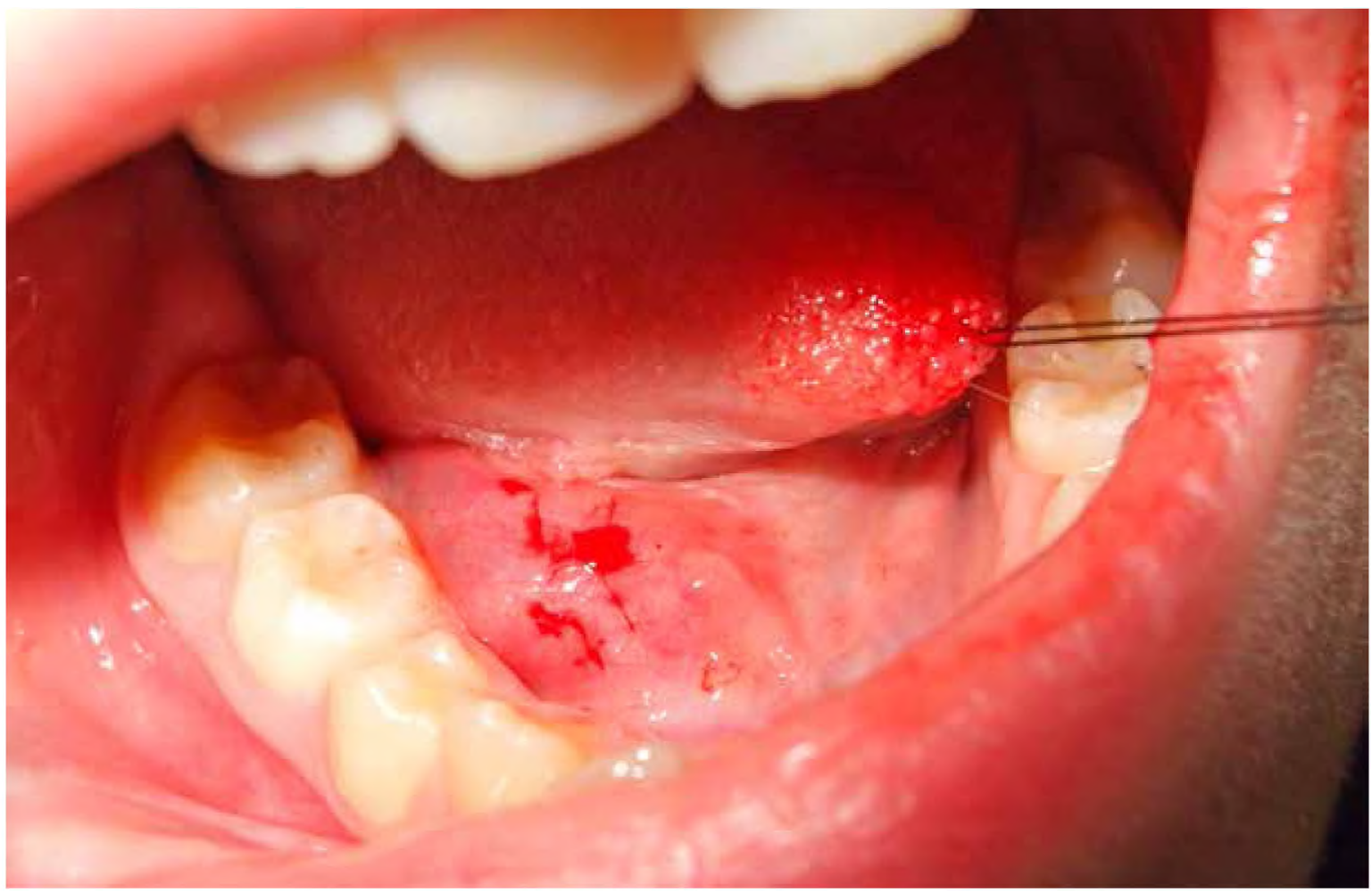

Técnica quirúrgica Marsupialización: Incisión inicial

pequeña porción de la pared superior, aspirar el contenido, contornear la cavidad y llenarla con gasa estéril; igualmente, algunas ránulas pueden tener origen más profundo y puede ser necesario remover la glándula sublingual asociada.

El índice de recurrencia de las ránulas no está relacionado con los patrones de tumefacción ni de acceso quirúrgico, pero, sí está íntimamente relacionado con los procedimientos quirúrgicos. Morita" considera que si las lesiones de la glándula sublingual son pseudoquistes es razonable su escisión, pero en aquéllas de tamaño menor de $2 \mathrm{~cm}$, y localización superficial, es conveniente y práctico realizar la marsupialización como técnica quirúrgica ${ }^{12}$. En nuestra práctica, la realizamos con muy buenos resultados, como se expone en el caso que presentamos.

Actualmente, se invoca la realización de la técnica de marsupialización mediante la radiación láser de $\mathrm{CO} 2$ con rayo a modo continuo con 4 watts de potencia, 8 con magníficos resultados tanto intraoperatorios, como en la evolución postoperatoria; así, el paciente tiene un postoperato- rio magnífico y, al no colocar sutura, se evita las molestias propias de su remoción ${ }^{13}$.

El tratamiento quirúrgico lógico está basado en la patogenia y la anatomía patológica de la lesión, y un enfoque dogmático del tratamiento de esta entidad no está justificado, porque es necesario individualizar el diagnóstico y plan de tratamiento de cada caso, para el logro de buenos resultados. 


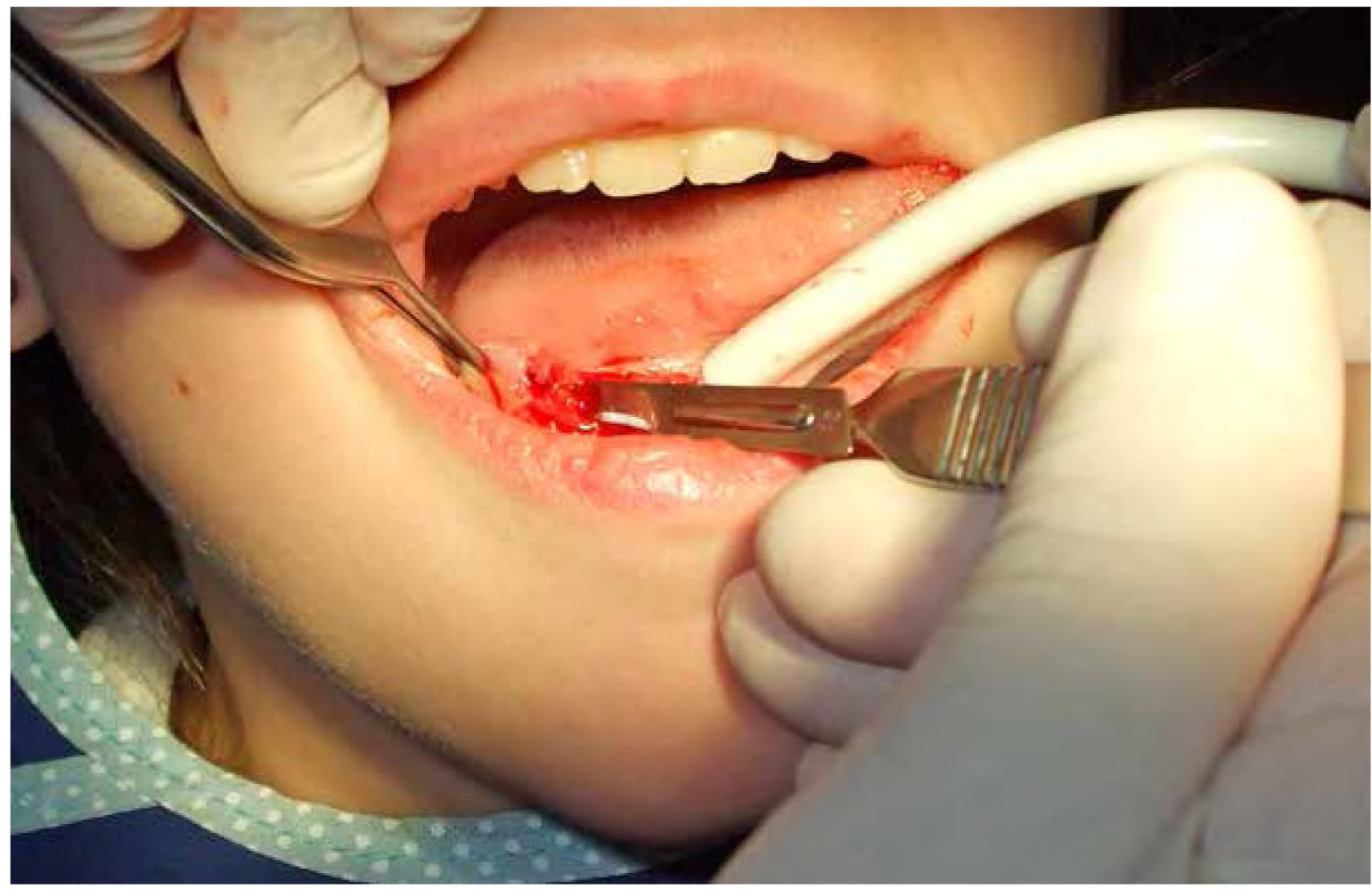

Incisión superior de la ránula.

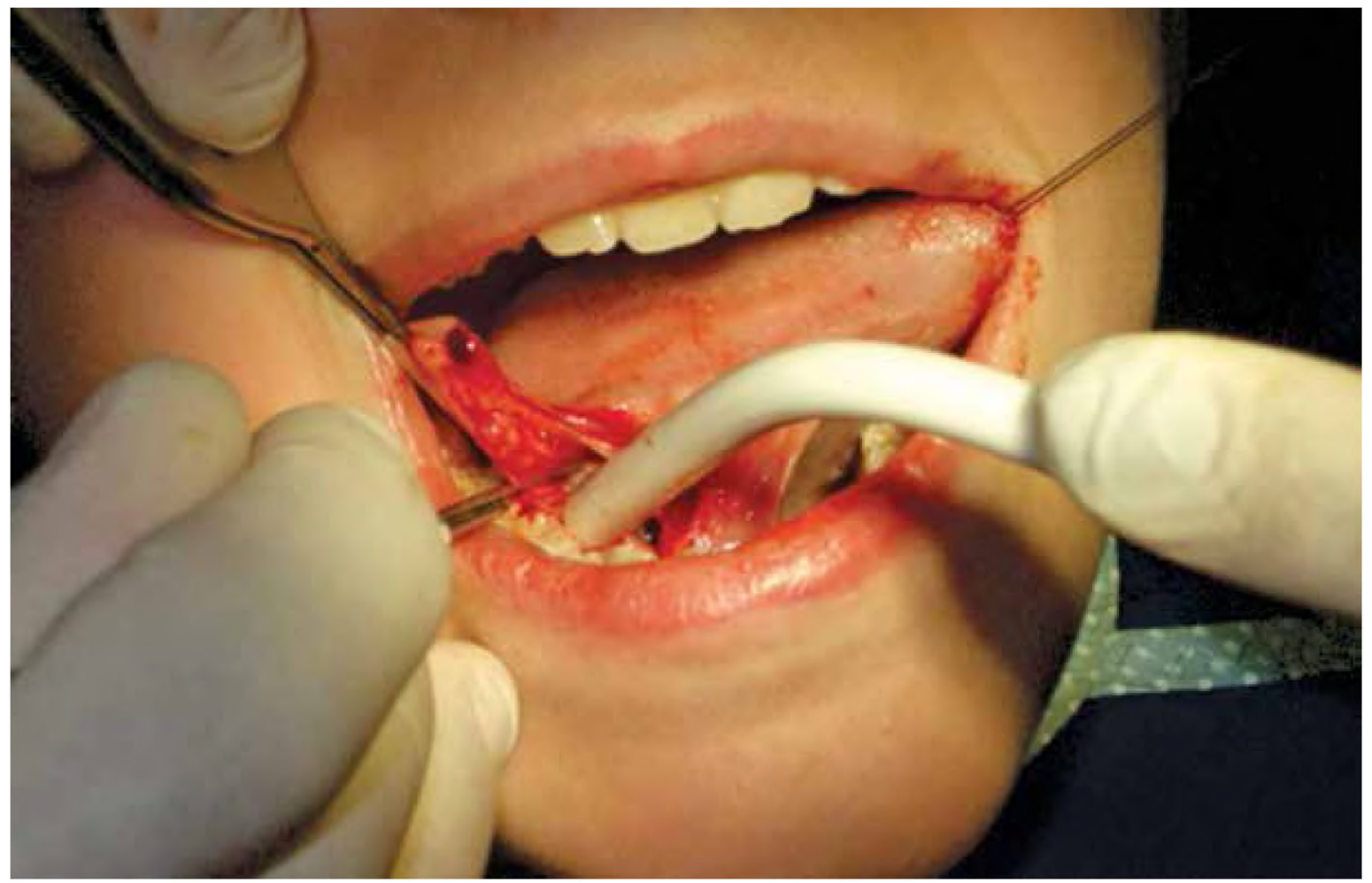

Eliminación de la porción superficial de la lesión. 

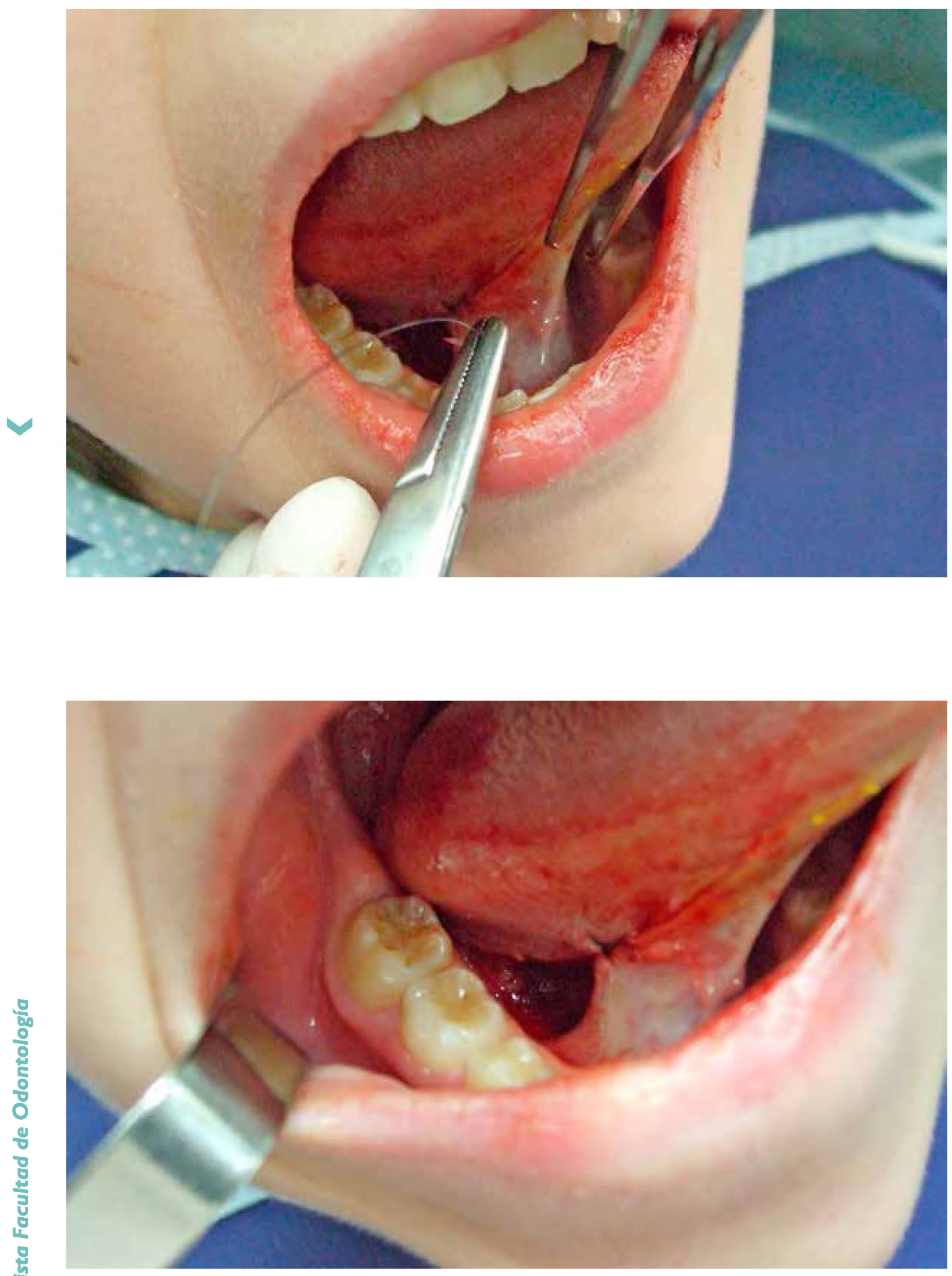

Sutura de la membrana quística a la mucosa del piso de la boca. 


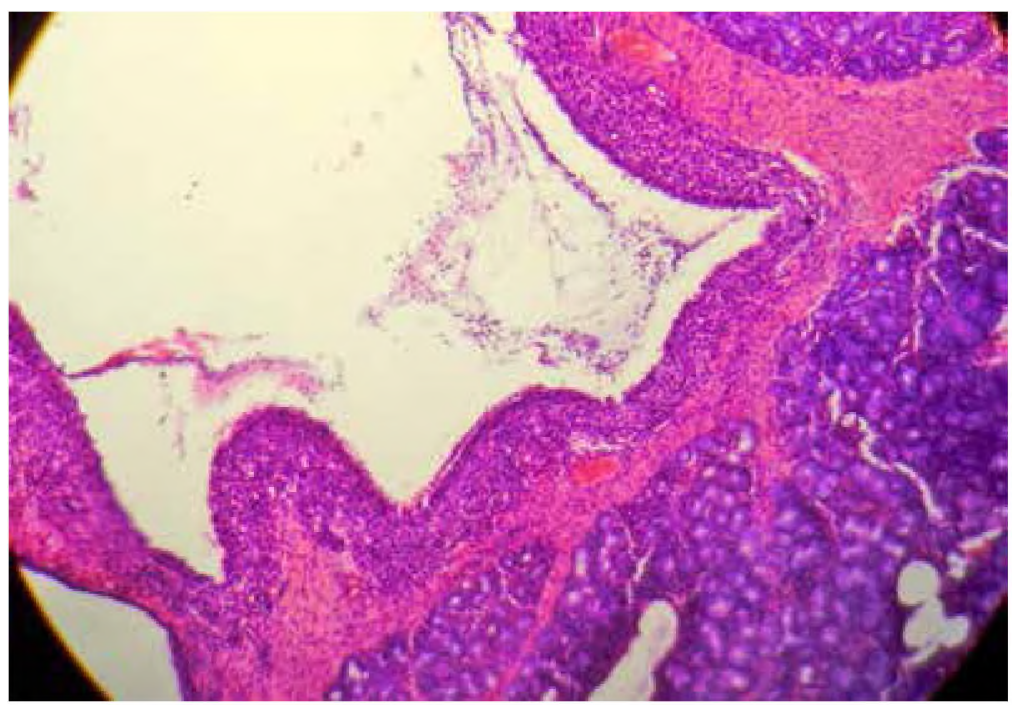

HIE IOX Se observa la cavidad seudoquistica rodeada de tejido conjuntivo fibroso y vasos ectasiados.

Técnica HIE IOX Se observa lobulillo glandular mucoso con ductos dilatados
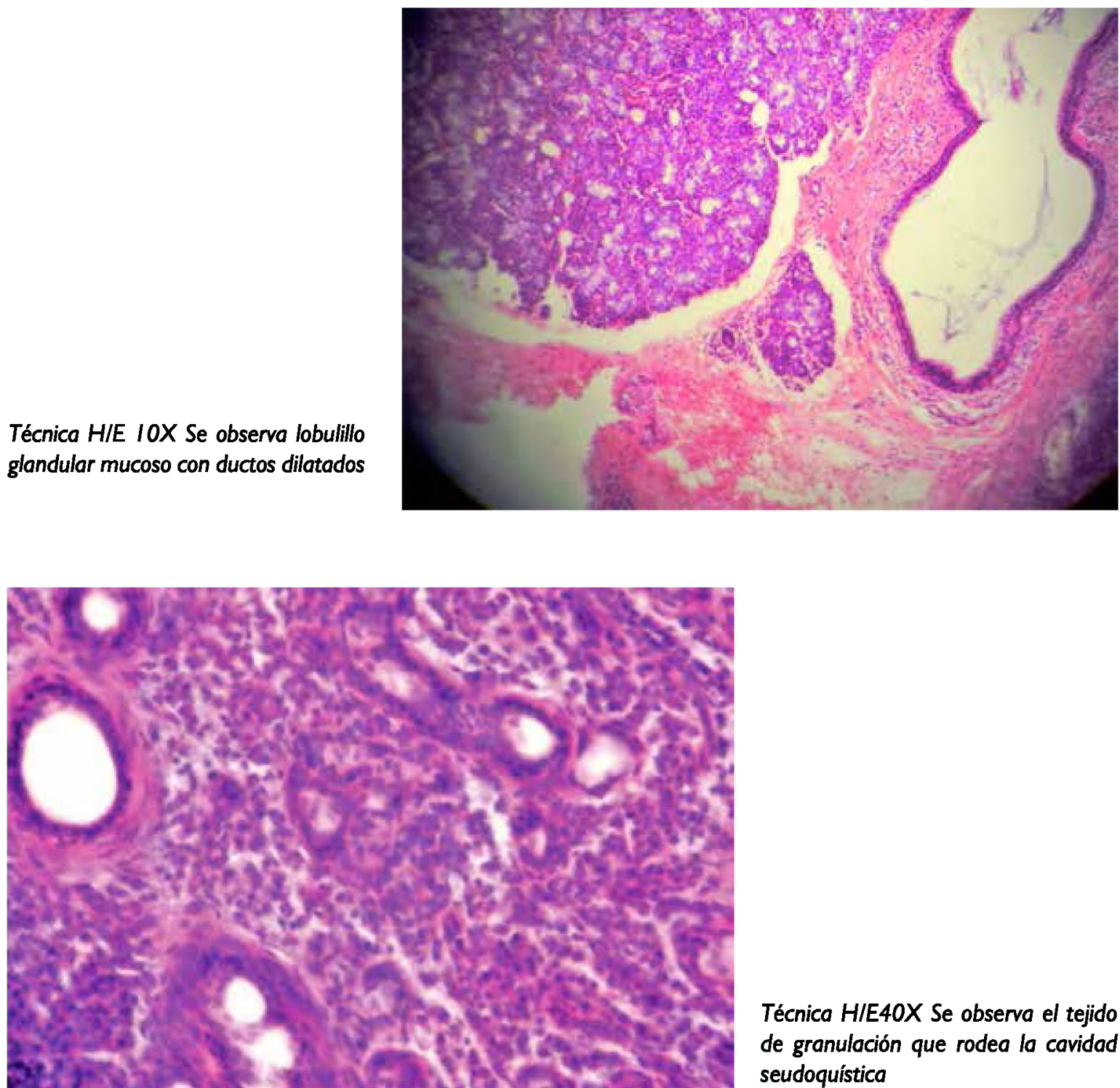

Técnica HIE40X Se observa el tejido de granulación que rodea la cavidad seudoquistica 


\section{Bibliografia}

I. Grinspan, David Enfermedades de la boca T.I Mundi 1982 Edición. Edit. Mundi S.A.I.C y F Año I 982 Bs. As Arg. Cap.XLI Pag. 2752 - 75.

2. Cabello Valladares Carmen Julia, García Orozco Karel, Pérez Enríquez Joaquín Antonio. Ránula sublingual: presentación de un paciente Medicentro 20I I; I5 (3): 267 - 269.

3. Regezi J. Sciubba J. Patología bucal. Tercera edición. Mc Graw-Hill Interamericana 2000: 224 226. México, DF.

4. Arenas, M. J. A., Juárez, G. R. J., Lagunes, L. M. A. Fenómeno de extravasación de glándulas salivales: a propósito de tres casos. Año 12. Núm. 38. 2011.758 -762.

5. Morton R. P., Ahmad Z., Jain P. Plunging ranula: congenital or acquired? J Podiatry Otorhinolaryngol. 2010 Jan; 142 (I): 104-7.

6. Marx R, Stern D. Oral and Maxillofacial pathology. Quinessence Publishing. Illinois EUA, Co, Inc. 2003: 51 I- 518.

7. Marlene Leyva Pérez.José Antonio Lahera Valdés. Dayana Díaz Díaz. Oviedo Pérez Pérez. Ránula del suelo de la Boca a propósito de un caso Instituto superior de Ciencias Médicas de la Habana Facultad de Estomatología de la Habana Servicio de Cirugía Maxilo Facial.

8. Ferrari. M; Gesi. A. Tratamiento quirúrgico de las glándulas salivales menores. Journal de Education Continua. 1995, 2 (8): 68 - 72.

9. Perez, Celenia y Jimenez, Cecilia. Mucoceles con localizaciones inusuales: Reporte de casos. Acta odontol. venez [online]. 2002, vol.40, n.2 [citado 2012-07-03], pp. 177 - 180

10. Kruger GO. Cirugía Bucomaxilotacial. 5ta ed. La Habana: Editorial Científico-Técnica; 1985, p.235.

I I. Morita Y, Sato K, Kawana M, Takahasi S, Ikarashi F. Treatment of ranula excision of the sublingual gland versus marsupialization. Auris Nasus Larynx. 2003 Aug; 30 (3): 3 I I - 4.

12. Noccoli-Filho W., Morosolli A. R. Surgical treatment of ranula with carbon dioxide laser radiation. Lasers Med Sci. 2004; 19 (I): 12 - 4.

13. Raspall G. Cirugía Maxilofacial. Patología quirúrgica de la cara, boca, cabeza y cuello. Ira ed. Madrid: Editorial Médica Panamericana; 1997, p. 445. 